\title{
2016 Presidential Election - The Winners and Losers in the Health Care Industry
}

\author{
Afua A. B. Agyekum \\ Ghana Institute of Management and Public Administration \\ Morgan State University, United States \\ Sharon Finney \\ Associate Professor of Accounting, Department of Accounting \& Finance \\ Morgan State University, United States \\ Ayishat Omar (Corresponding author) \\ Assistant Professor of Accounting, Department of Accounting and Finance \\ Rowan University, United States \\ E-mail: omar@rowan.edu
}

Alex P Tang

Professor of Finance, Department of Accounting \& Finance

Morgan State University, United States

Received: October 18, 2019 Accepted: November 22, 2019 Published: December 1, 2019

doi:10.5296/ijafr.v9i4.15637 URL: https://doi.org/10.5296/ijafr.v9i4.15637

\begin{abstract}
The 2016 presidential election had important implications for the country's health care policies. In this study, we examine the health care industry stock returns associated with the 2016 presidential campaign. We use both market model and seemingly unrelated regression (SUR) methodologies to estimate abnormal stock returns of each health care sector associated
\end{abstract}


with each event. Our results are robust and mostly consistent with our arguments. The regression analysis further augments our event study results. We find that, during the pre-election period, the Biological Products, Health Insurance, and Major Pharmaceuticals all suffer significantly negative cumulative average abnormal returns (CAARs). The Hospital/Nursing Management and Medical/Dental Instruments fare reasonably well. Our interpretation is that the market takes a dim view on the Biological Products, Health Insurance, and Major Pharmaceuticals sectors when the consensus is that Clinton would win the election. When the election is over, the fortune reverses for the Biological Products and Major Pharmaceuticals. It continues when President Trump meets with the health care industry CEOs. The regression results further confirm our event study results. Our study shows that the 2016 election has a significant impact on the affected industry and the firms in the industry. However, even in the same broad industry, sectors/firms fare differently. Our study shows that it is important to identify the winning and losing sectors and examine the impact of an election on various sectors in a detailed and refined way.

Keywords: 2016 Campaign, 2016 Election, Health care industry, Event studies

\section{Introduction}

Repealing Obamacare became Trump's signature promise during his campaign trail. He continued making that promise when he became the presumptive Republican candidate and the President. As a candidate, president-elect, and president, Trump has repeatedly pointed to the repeal of Obamacare as a top priority and a key reason why he wanted to be president. He has promised to repeal Obamacare many times. His most commonly used campaign slogan was "repeal and replace Obamacare".

On the other hand, Trump's major Democratic presidential contender, Senator Clinton supported retaining and expanding the ACA and would make health insurance enrollment easier through the law. In the meantime, she would fix the things which did not work in the ACA. In a nutshell, she would "save what works" about the ACA and tame its rising costs. In summary, Clinton's position on the ACA was to save and improve it.

In this study, we examine the health care industry stock returns associated with the 2016 presidential campaign. We examine in detail the impacts of important political events on the returns of health care stocks. Because the presidential campaign was a long and fluid process, we carefully identify the events. Also, the health care industry is very diverse, representing a broad range of sectors. Those diverse sectors would not be affected uniformly. We hypothesize and identify which sectors would benefit or lose under each event. Then, we use event study methodologies to document the abnormal stock returns of each health care sector associated with each event.

Our paper is organized as follows. In Section 2, we review the opposing views on the ACA and develop our hypotheses. We explain our research design and methodologies in Section 3. The empirical results are presented and discussed in Section 4. We present conclusions in Section 5. 


\section{Opposing Views on the ACA}

The ACA has three important aspects. The centerpiece of the ACA is the individual mandate which is supported by the employer mandate and the exchanges i.e., marketplaces. The individual mandate requires most Americans to have health insurance or pay a penalty when they file their federal income tax return. Individuals must have "minimal essential coverage," which includes: coverage under an employer-sponsored plan, coverage under an individual insurance policy, coverage under a government-sponsored plan such as Medicare or Medicaid or U.S.-issued expatriate insurance coverage (IRS, 2018). The main rationale for the individual mandate is to prevent the "adverse selection" problem; those who are healthy and believe that they will remain so won't buy insurance while those who are sick or think they may become so will buy insurance.

Although the main goal of the individual mandate was to preempt the adverse selection problem, it made the situation no better than before. Many young adults find that it was financially advantageous for them to forgo health insurance, pay the moderate mandate penalty, and personally cover their own health care expenses. While this would leave them vulnerable to extremely high medical bills if they endured a catastrophic illness or accident, it created big challenges for the ACA in its push to enroll the young adults. Those young adults who had remained under the radar of the individual mandate were coined "young invincibles".

The second major aspect of the ACA was the employer mandate. The employer mandate or employer penalty required that employers of more than fifty full-time employees must either provide health insurance for full-time employees or pay a penalty for not doing so. The mandate or penalty was intended, of course, to encourage employers to provide health insurance.

The third aspect of the ACA was the exchanges. The exchanges or market-places were where people could purchase health insurance from participating insurance companies. They were also where the major government assistance was provided. Those who purchase insurance in an exchange typically receive a tax credit. The ACA prohibited insurers from denying access to coverage based on pre-existing conditions and prohibited them from charging different premiums to individuals based on their health. Everyone was in one big insurance pool, sharing in the average cost in the same exchange.

To keep premiums affordable, it was vital that the law attract a substantial number of young and healthy "invincibles". They were less likely to need critical care to balance out older and sicker uninsured people who enrolled and would be costlier to the system. However, critics of the ACA argued that the insurance pool system exacerbated the adverse selection problem, raised the average cost of doing business for insurers, and led them to raise premiums on everyone. That, in turn, could cause even more healthy young people to drop insurance because they no longer saw it as good value, again requiring insurers to increase premiums, and so on, resulting in a "death spiral." 
Indeed, the Department of Health and Human Services (HHS) reported in early January 2014 that 24 percent of Obamacare's enrollees were young people (Kliff, 2014). According to George Mason University's Mercatus Center, the figures remained at 36 percent in both 2015 and 2016. It was better than the figure in 2014, but still were way below the initial weighted projection for 2015 and 2016 of 47 percent. The lack of incentives for young, healthy, and therefore cheap-to-insure individuals to sign up for coverage and the possibility that coverage may not be affordable enough for the previously uninsured to enroll became the hallmarks of the reform's complexity and its problems.

Since the makeup of the Obamacare risk pools, i.e., the balance of healthy and sick participants in a plan, was sicker and costlier than insurers hoped, most insurance companies, therefore, had experienced losses in the exchanges, often large losses. It only made sense that most exchange insurers would request significant rate increases. Should regulators reject large premium increases, participating insurance companies could simply decide to cut their losses and drop off the exchanges altogether. In 2016, eight states had Obamacare plans whose premiums increased by at $30 \%$ or more (Tuttle, 2016).

Even with large premium increases, insurance companies still suffered almost \$2 billion in losses in 2016 according to Bloomberg Business Week's August 17, 2016 report. Initially, they scaled back their presences in some states. Eventually, the two largest insurance companies, UnitedHealth and Aetna, announced in 2016 that they would pull out from most exchanges in 2017.

Thus, with all those issues, the ACA became a controversial and hot button campaign topic. Both candidates had tried to score points with voters by offering their opinions and solutions of dealing with the ACA. Candidate Clinton had made the ACA the centerpiece of her health care plan. She embraced the law and promised to defend and expand it. Her plan to expand Obamacare consisted of a slew of incremental measures that together were intended to cut costs and improve coverage for patients. On the other hand, Trump believed that the ACA was totally broken. It could not be fixed, and repeal was the only fix. Here was one of his typical remarks on the ACA - "Completely repeal Obamacare. Our elected representatives must eliminate the individual mandate. No person should be required to buy insurance unless he or she wants to".

\section{Literature Review and the Impact of the ACA on Stock Returns}

\subsection{Literature Review}

Beginning with the seminal paper of Fama et al. (1969), researchers have applied event study methodology to study the effect of policy changes, not only in this country, but in many other countries. Since the literature on event study is voluminous, we focus our attention, in this study, on the literature of using event study methodology to examine recent changes in health care policies and practices.

Topping, Carroll, and Lindley (1997) examine the response of hospital stocks to the Medicare Prospective Payment System (PPS) legislation and its resulting effect on the ability of hospitals to generate funds for expansion and growth. They find that hospital stocks react 
negatively to PPS legislation. This result lends credence to qualitative evidence showing that hospitals' capital positions are impaired because of the PPS legislation; i.e., hospitals' profit margins fall, bond ratings drop, borrowing costs increase; the rate of hospital bond defaults increase and capital improvements are delayed (Topping et al., 1997).

Several studies have used event study methodology to examine the impact of the passage and Supreme Court upholding of the ACA on health care industry stock prices. Al-Ississ and Miller (2013) use the surprise election of Republican Scott Brown to the U.S. Senate to examine the ACA's impact on the health care industry. Their paper shows a strong association between Scott Brown's victory and positive abnormal returns for firms in the healthcare sector, particularly in the health insurance and pharmaceutical sectors.

Bell (2011) uses prediction markets, i.e., Public Option Contract and the Obamacare Contract, to examine Obamacare. Evidence from the Obamacare Contract suggests that the winners of the reform effort are health care facilities (hospitals), managed care firms, and brand pharmaceuticals, while medical device distributors, health services, and generic pharmaceuticals are losers.

Hartley (2012) examines the effect of this Supreme Court ruling. He focuses on firms within different health care sectors (managed care, biotech, hospitals, health care services, and pharmaceuticals). Specifically, he finds significantly negative abnormal return for managed care and biotechnology stocks, but significantly positive abnormal returns for hospitals and health care services stocks. In addition, Ababneh and Tang (2013) find that the law has a negative effect on health insurance companies, and on generic drug makers. On the other hand, it has a positive effect on hospitals and on brand-name drug makers.

Dong (2014) investigates the effect of the Congress's passage of the ACA in 2010 and the Supreme Court's upholding of the Act in 2012 on the stock returns of health care firms. He finds that the 2-day $(-1,0)$ cumulative abnormal returns (CARs) are significantly positive for hospitals on both events, and the CARs are also significant for doctor clinics on the passage day and specialty outpatient facilities on the upholding day. None of the other sectors have significant CARs.

Borochin and Golec (2016) use both the stock and option markets to investigate the House of Representatives passage of the ACA and the subsequent Supreme Court ruling on the ACA's constitutionality. They find that the passage of the ACA and the Supreme Court ruling have significant and positive net effects on the hospital and health insurance industries, but not the pharmaceutical industry.

Blau et al. (2016) find that the passage of the ACA has a negative effect on health insurance companies and medical device companies, while having a positive influence on firms in the health care sector. Topping et al. (2018) examine the impact of Supreme Court's upholding of the ACA on insurance stocks. Their results provide weak support for a negative market reaction hypothesis, with returns among insurers varying significantly. We summarize the results documented from the above studies in Table 1. 
Table 1. Summary of event studies on the impact of the ACA

\begin{tabular}{|c|c|c|}
\hline & $\begin{array}{l}\text { Proposing/Passing of the } \\
\text { ACA }\end{array}$ & $\begin{array}{l}\text { Upholding of the ACA by } \\
\text { the Supreme Court }\end{array}$ \\
\hline \multirow[t]{2}{*}{ Ababneh and Tang (2013) } & $\begin{array}{l}\text { Winners: hospitals and brand } \\
\text { pharmaceuticals }\end{array}$ & \\
\hline & $\begin{array}{l}\text { Losers: insurers and generic } \\
\text { pharmaceuticals }\end{array}$ & \\
\hline \multirow[t]{2}{*}{ Al-Ississ and Miller (2013) } & Winners: hospitals. & \\
\hline & $\begin{array}{l}\text { Losers: insurers, } \\
\text { pharmaceutical firms and } \\
\text { medical device manufacturers }\end{array}$ & \\
\hline
\end{tabular}

Bell (2011)

Winners: health care

facilities (hospitals),

managed care firms, and

brand pharmaceuticals

Losers: medical device

distributors, health

services, and generic

pharmaceuticals

Hartley (2012)

Winners: hospitals and health care services stocks

Losers: managed care and biotechnology stocks

\begin{tabular}{lll}
\hline Dong (2014) & $\begin{array}{l}\text { Winners: hospitals and doctor } \\
\text { clinics }\end{array}$ & $\begin{array}{l}\text { Winners: specialty } \\
\text { outpatient facilities }\end{array}$ \\
\hline Borochin and Golec (2016) & Winners: hospitals & Winners: hospitals \\
& & Losers: insurers \\
\hline
\end{tabular}

Blau et al. (2016)

Winners: health care

providers

Losers: insurers, device

companies

Hilliard et al. (2018)

Losers: insurers 


\section{Ml Macrothink}

International Journal of Accounting and Financial Reporting

ISSN 2162-3082

2019, Vol. 9, No. 4

There is an ongoing debate on the effectiveness of the ACA. Geyman (2015) compares the goals of the ACA to the achievements attained and argue that health care costs are still on the rise with its containment becoming more challenging. However, Hall and McCue (2016) believe that the ACA could improve health insurance pricing in the foreseeable future. In their article, they discuss how the ACA has transformed the financial performance of health insurance companies. They argue that a quarter of insurers performed worse than others, especially in the first full year of the reform, but that costs can be manageable down the line.

\subsection{Impact of the 2016 Election on Health Care Stocks}

When we look at the totality of the evidence presented in Table 1, it appears that the ACA benefits the hospital and health care services stocks and hurts the health insurance stocks. There is some evidence that the law also hurts the pharmaceutical, biotechnology, and medical device firms. For the other health care stocks, the evidence is not conclusive.

Based upon the summary presented in the table, we conjecture that any 2016 presidential campaign events favoring Clinton would be good for the winners of the ACA, and bad for the losers of the ACA. On the other hand, any campaign event favoring candidate Trump would be bad for the winners of the ACA and good for the losers of the ACA.

Most of the studies we review focus on one or two events: The passage of the ACA in the House and the Supreme Court's upholding of the law. Our study, instead, examines the impact of a series of 2016 presidential election events on various health care sectors. The events include the dates that Clinton and Trump declared their candidacies, the dates they became the presumptive candidates of the Democratic and Republican parties, and the day after the election.

\section{Research Design}

\subsection{Data Collection}

The sample period starts from April 12, 2015, when Clinton announced her candidacy to March 24, 2017, when the American Health Care Act of (AHCA) was withdrawn from the House. The event dates for this study are retrieved and cross examined from various news agencies such as Dow Jones, Reuters, New York Times, CNN, Fox News, etc. We present a summary of the event dates in Table 2.

Table 2. Chronicle of 2016 presidential election selected events

\begin{tabular}{ll}
\hline Event & Date \\
\hline Hillary Clinton announced her candidacy & $4 / 12 / 2015$ \\
\hline Donald Trump announced his candidacy & $6 / 16 / 2015$ \\
\hline Donald Trump became Republicans' presumptive candidate & $5 / 4 / 2016$ \\
\hline
\end{tabular}


We employ an archival research design to assess the market impact of five significant events from the candidacy announcement to the day after the election. We first retrieve a list of all health care companies from NASDAQ company list. The list of company names and ticker symbols is used to identify Cusip from Compustat. The resulting list is then used to access the Permno for the companies from CRSP to enable data analyses on Eventus. There are twelve health care sectors according to the NASDAQ classification.

Out of the twelve sectors, we select five major sectors according to the following criteria: the number of firms in the sectors, representativeness of the sectors, and the relevance of the sectors in literature. Based on these classifications, the sectors selected are the Biological Products (BIO, 36 firms), Health Insurance (INS, 6 firms) Hospital/Nursing Management (HOS, 12 firms), Major Pharmaceuticals (PHA, 148 firms), Medical/Dental Instruments (MED, 35 firms).

\subsection{Methodologies}

In this study, we use two methodologies to measure the impacts of the five events on the five health care sectors' stock returns: Market model methodology and the seemingly unrelated regression (SUR) methodology.

\subsubsection{Market Model Methodology}

The abnormal returns are measured using the Brown and Warner (1985) market model. The market model has been widely used in event studies and is defined as:

$$
A_{i t}=R_{i t}-\left(\hat{\alpha}_{i}+\hat{\beta}_{i} R_{m t}\right)
$$

Where $\mathrm{R}_{\mathrm{it}}$ is the rate of return of the common stock of security $i$ on day $t$, and $\mathrm{R}_{\mathrm{mt}}$ is the rate of return on an equally-weighted market index on day t. The $\hat{\alpha}_{i}$ and $\hat{\beta}_{i}$ are ordinary least squares estimates of $\alpha_{i}$ and $\beta_{i}$. We estimate the OLS parameters using a common 100-day estimation period. The abnormal returns are measured over three window periods: -5 to $-1,0$ to +1 , and +2 to +5 . We use Eventus to facilitate our computation of market model abnormal returns and $\mathrm{Z}$ statistics to assess the statistical significance of the abnormal returns.

\subsubsection{Seemingly Unrelated Regression (SUR) Methodology}

To check for robustness, we also estimate the abnormal returns using seemingly unrelated regression (SUR) methodology. Similar to the methodology used by Schipper and Thompson (2014), SUR considers the contemporaneous dependence of disturbances. Therefore, the use of SUR will yield more efficient estimates relative to the standard event study methodology 
that requires residuals to be identically and independently distributed (Nguyen and Tang, 2011).

\subsubsection{Regression Analysis}

We estimate the following regression model:

$$
\begin{aligned}
\mathrm{CAR} & =\beta_{0}+\beta_{1} \mathrm{BIO}+\beta_{2} \mathrm{INS}+\beta_{3} \mathrm{HOS}+\beta_{4} \mathrm{PHA}+\beta_{5} \mathrm{FM} \_\mathrm{SZ}+\beta_{6} \mathrm{MTB}+\beta_{7} \mathrm{LEV} \\
& +\beta_{8} \mathrm{ROA}+\beta_{9} \mathrm{CS} \_\mathrm{TA}+\beta_{10} \mathrm{RD} \_\mathrm{TA}
\end{aligned}
$$

In which, CAR is the $(0,1)$ two-day abnormal returns on post-election days of November $9^{\text {th }}$ and $10^{\text {th }}, 2016$. BIO is a dummy variable that takes the value of one for firms that operate in the BIO Product sector, otherwise zero. INS is a dummy variable that takes the value of one for firms that operate in the INS sector, otherwise zero. HOS is a dummy variable that equals one for firms that operate in the HOS sector, otherwise zero. PHA is a dummy variable that equals one for firms that operate in the PHA sector, otherwise zero.

We also include relevant control variables in the model. FM_SZ is firm size, estimated as the natural logarithm of total assets. We expect the larger health care firms will be affected more on the post-election day. MTB is market to book value. It is computed as the ratio of market value of equity to book value of assets. Because it is a measure of a firm's growth opportunity, we expect firms with higher MTB will be affected more on the post-election day.

LEV represents leverage, the ratio of debt to total assets. ROA is the ratio of earnings before interest and tax to total assets. We don't make predictions on the sign of these two control variables. CS_TA is the ratio of capital expenditure to total assets and RD_TA is the ratio of research and expenditure to total assets. We expect the sign of these two variables will go in the same direction of the post-election two-day CAR.

\section{Results}

\subsection{Event Study Results}

We examine the events in several periods: -5 to $-1,0$ to +1 and +2 to +5 . Examining the period of -5 to -1 detects whether there is any pre-reaction to the event. The next period is normally used in the event study literature to investigate market reactions; the last period, +2 to +5 , is to examine if there are any post-event adjustments. We first use market model methodology to carry out the event study and present the results in Table 3. We then use SUR to confirm our market model results and present the results in Table 4.

\subsubsection{Clinton's Candidacy Announcement}

In the period of -5 to -1, BIO has significantly positive CAAR. On the other hand, the INS has significantly negative CAAR. None of the other three sectors have significant CAAR. In the two-day announcement period of 0 and +1 , the INS continues to have significantly negative CAAR. 


\section{Mll Macrothink}

International Journal of Accounting and Financial Reporting

ISSN 2162-3082

2019, Vol. 9, No. 4

In the post-event period of +2 to +5 , other than the HOS, all other four sectors suffer significantly negative CAARs. It appears that the investors take a pretty dim view on the overall health care industry associated with this event.

The SUR event study results for the periods -5 to -1 and +2 to +5 do not suggest any significant abnormal returns. However, in the period of 0 and +1 , the SUR result for the PHA is significantly positive.

\subsubsection{Trump's Candidacy Announcement}

In the period of -5 to -1 , both the INS and HOS have significantly positive CAARs. On the other hand, PHA has a significantly negative CAAR. In the announcement period of 0 and 1 , PHA has significantly negative CAAR. The MED has mild and positive CAAR. During the post-announcement period of +2 to +5 , BIO continues to have significantly negative CAAR. On the other hand, PHA has positive CAAR along with MED. It seems that there are no clear winners or losers associated with this event. Very likely, the stock market doesn't think Trump is a serious contender at this early stage of the Presidential campaign.

The magnitudes of the SUR returns are similar to those discussed above. For the periods -5 to -1 and 0 to +1 , MED has significantly negative CAARs.

\subsubsection{Trump's Presumptive Nomination}

In the period of -5 to $-1, \mathrm{BIO}$, INS, and PHA all have significantly negative CAARs, at least, at the 0.10 significance level. In the event period of 0 and +1 , the same three sectors continue to have significantly negative CAARs. On the other hand, MED has a significant CAAR of $0.67 \%$.

In the period of +2 to +5 , PHA continues to have significantly negative CAAR. It appears that the BIO, INS, and PHA all fare poorly during this event; especially PHA. There could be two different interpretations. First, investors expect that these sectors will suffer if Trump becomes the President. Second, Trump is expected not to beat Clinton and these sectors will suffer under the Clinton administration. We will have a better understanding about which interpretation prevails over the other interpretation when we examine the next event. 
Table 3. Market model results

\begin{tabular}{|c|c|c|c|c|c|c|c|c|c|c|}
\hline & \multicolumn{2}{|c|}{ Biological Products } & \multicolumn{2}{|c|}{$\begin{array}{l}\text { Health } \\
\text { Companies }\end{array}$} & \multicolumn{2}{|c|}{$\begin{array}{l}\text { Hospital/Nursing } \\
\text { Management }\end{array}$} & \multicolumn{2}{|c|}{ Major Pharmaceuticals } & \multicolumn{2}{|c|}{$\begin{array}{l}\text { Medical/Dental } \\
\text { Instruments }\end{array}$} \\
\hline & \multicolumn{2}{|c|}{ Market Model } & \multicolumn{2}{|c|}{ Market Model } & \multicolumn{2}{|c|}{ Market Model } & \multicolumn{2}{|c|}{ Market Model } & \multicolumn{2}{|c|}{ Market Model } \\
\hline & CAAR & Z-VALUE & CAAR & Z-VALUE & CAAR & Z-VALUE & CAAR & Z-VALUE & CAAR & Z-VALUE \\
\hline \multicolumn{11}{|c|}{ APRIL 12, 2015} \\
\hline$[-5,-1]$ & $1.79 \%$ & $1.57^{\circ}$ & $-2.15 \%$ & $-2.51^{\cdots *}$ & $-0.25 \%$ & -1.09 & $1.00 \%$ & 0.73 & $0.10 \%$ & 0.16 \\
\hline$[0,1]$ & $0.78 \%$ & 1.19 & $-0.64 \%$ & $-1.44^{*}$ & $-0.27 \%$ & 0.13 & $0.06 \%$ & 0.63 & $-0.50 \%$ & -0.75 \\
\hline \multicolumn{11}{|c|}{ JUNE 16,2015} \\
\hline$[-5,-1]$ & $-0.95 \%$ & -1.19 & $1.48 \%$ & $1.76^{* *}$ & $0.88 \%$ & $2.08^{* *}$ & $-1.49 \%$ & $-4.25^{* * *}$ & $-0.28 \%$ & -1.17 \\
\hline$[0,1]$ & $-0.23 \%$ & -1.19 & $0.36 \%$ & 0.15 & $-0.32 \%$ & -1.18 & $-0.33 \%$ & $-1.63^{\circ}$ & $0.45 \%$ & $1.35^{\circ}$ \\
\hline$[2,5]$ & $-0.91 \%$ & $-2.12^{* *}$ & $0.56 \%$ & 1.22 & $0.57 \%$ & 0.86 & $1.36 \%$ & $3.97^{\ldots *}$ & $0.53 \%$ & $1.58^{\circ}$ \\
\hline \multicolumn{11}{|c|}{ MAY 4,2016} \\
\hline \multicolumn{11}{|c|}{ JUNE 7, 2016} \\
\hline$[-5,-1]$ & $-1.16 \%$ & 0.03 & $-0.59 \%$ & -0.65 & $-0.36 \%$ & -0.60 & $-0.10 \%$ & $-1.59^{\circ}$ & $-0.17 \%$ & -0.11 \\
\hline$[0,1]$ & $-2.51 \%$ & $-2.75^{\cdots *}$ & $-0.19 \%$ & -0.08 & $0.42 \%$ & $1.86^{* *}$ & $-2.13 \%$ & $-8.85^{* * *}$ & $0.14 \%$ & 0.13 \\
\hline$[2,5]$ & $-1.28 \%$ & 0.03 & $-0.40 \%$ & -0.65 & $-1.91 \%$ & $-1.41^{*}$ & $-0.34 \%$ & $-1.61^{\circ}$ & $2.05 \%$ & $3.69^{* * *}$ \\
\hline \multicolumn{11}{|c|}{ NOVEMBER 9, 2016} \\
\hline$[-5,-1]$ & $1.73 \%$ & $1.77^{* *}$ & $2.24 \%$ & 1.19 & $1.43 \%$ & $1.50^{*}$ & $-1.48 \%$ & -0.22 & $-0.49 \%$ & -0.48 \\
\hline$[0,1]$ & $4.80 \%$ & $4.29^{* * *}$ & $-0.82 \%$ & 1.19 & $-3.62 \%$ & $-2.59^{* * *}$ & $4.21 \%$ & $8.78^{* *}$ & $-1.36 \%$ & -0.97 \\
\hline$[2,5]$ & $-2.91 \%$ & $-2.16^{* *}$ & $-0.44 \%$ & 0.62 & $0.07 \%$ & -0.13 & $-3.82 \%$ & $-5.54^{\ldots *}$ & $-1.91 \%$ & $-2.18^{* *}$ \\
\hline
\end{tabular}

Table 4. SUR results

\begin{tabular}{|c|c|c|c|c|c|c|c|c|c|c|}
\hline & \multicolumn{2}{|c|}{ Biological Products } & \multirow{2}{*}{$\begin{array}{l}\begin{array}{l}\text { Health } \\
\text { Companies }\end{array} \\
\text { SUR }\end{array}$} & \multirow[t]{2}{*}{ Insurance } & \multicolumn{2}{|c|}{$\begin{array}{l}\text { Hospital/Nursing } \\
\text { Management }\end{array}$} & \multicolumn{2}{|c|}{ Major Pharmaceuticals } & \multicolumn{2}{|c|}{$\begin{array}{l}\text { Medical/Dental } \\
\text { Instruments }\end{array}$} \\
\hline & SUR & & & & SUR & & SUR & & SUR & \\
\hline & CAAR & F-VALUE & CAAR & F-VALUE & CAAR & F-VALUE & CAAR & F-VALUE & CAAR & F-VALUE \\
\hline \multicolumn{11}{|c|}{ APRIL 12, 2015} \\
\hline$[-5,-1]$ & $0.69 \%$ & 0.05 & $-2.28 \%$ & 1.73 & $0.07 \%$ & 0.00 & $1.74 \%$ & 2.42 & $-0.04 \%$ & 0.00 \\
\hline$[0,1]$ & $1.11 \%$ & 0.35 & $-1.17 \%$ & 1.18 & $-0.15 \%$ & 0.03 & $1.29 \%$ & $5.88^{* *}$ & $-0.26 \%$ & 0.09 \\
\hline$[2,5]$ & $-1.06 \%$ & 0.16 & $-2.37 \%$ & 2.37 & $-0.60 \%$ & 0.20 & $0.59 \%$ & 0.47 & $-1.74 \%$ & 1.98 \\
\hline \multicolumn{11}{|c|}{ JUNE 16,2015} \\
\hline$[-5,-1]$ & $-0.51 \%$ & 0.04 & $0.93 \%$ & 0.28 & $1.00 \%$ & 0.53 & $-2.93 \%$ & $13.16^{* *}$ & $-0.74 \%$ & 0.33 \\
\hline$[0,1]$ & $-0.66 \%$ & 0.15 & $0.19 \%$ & 0.03 & $-0.69 \%$ & 0.66 & $-1.15 \%$ & $6.70^{* * *}$ & $0.49 \%$ & 0.36 \\
\hline$[2,5]$ & $-0.96 \%$ & 0.16 & $0.18 \%$ & 0.01 & $0.61 \%$ & 0.25 & $0.95 \%$ & 1.59 & $0.83 \%$ & 0.52 \\
\hline \multicolumn{11}{|c|}{ MAY 4, 2016} \\
\hline$[-5,-1]$ & $-2.79 \%$ & 1.83 & $-3.24 \%$ & $3.62^{\circ}$ & $0.49 \%$ & 0.02 & $-3.67 \%$ & $22.29^{* *}$ & $-0.21 \%$ & 0.04 \\
\hline$[0,1]$ & $-2.60 \%$ & $4.07^{* *}$ & $-0.36 \%$ & 0.11 & $1.78 \%$ & 0.80 & $-3.79 \%$ & $71.87^{\ldots *}$ & $0.26 \%$ & 0.18 \\
\hline$[2,5]$ & $-1.41 \%$ & 0.60 & $-0.71 \%$ & 0.22 & $-3.40 \%$ & 1.42 & $-3.07 \%$ & $18.98^{* * *}$ & $-1.99 \%$ & $4.91^{* *}$ \\
\hline \multicolumn{11}{|c|}{ JUNE 7, 2016} \\
\hline$[-5,-1]$ & $-1.94 \%$ & 0.83 & $-0.12 \%$ & 0.01 & $-0.78 \%$ & 0.06 & $2.58 \%$ & $3.34^{\circ}$ & $-0.21 \%$ & 0.05 \\
\hline$[0,1]$ & $-2.62 \%$ & $3.92^{* *}$ & $-0.32 \%$ & 0.10 & $-0.47 \%$ & 0.05 & $-1.00 \%$ & 2.41 & $-0.42 \%$ & 0.48 \\
\hline$[2,5]$ & $-0.60 \%$ & 0.10 & $0.25 \%$ & 0.03 & $0.32 \%$ & 0.01 & $-0.44 \%$ & 0.26 & $-2.26 \%$ & $6.32^{* *}$ \\
\hline \multicolumn{11}{|c|}{ NOVEMBER 9, 2016} \\
\hline$[-5,-1]$ & $2.22 \%$ & 0.92 & $2.91 \%$ & $3.21^{\circ}$ & $1.02 \%$ & 0.27 & $-1.59 \%$ & $6.08^{* *}$ & $-3.56 \%$ & $8.15^{\circ *}$ \\
\hline$[0,1]$ & $5.44 \%$ & $13.71^{* *}$ & $-1.61 \%$ & 2.41 & $-4.30 \%$ & $12.18^{* * *}$ & $4.21 \%$ & $104.78^{\circ *}$ & $-0.29 \%$ & 0.13 \\
\hline$[2,5]$ & $-1.44 \%$ & 0.48 & $-0.03 \%$ & 0.00 & $3.49 \%$ & $4.01^{* *}$ & $-3.59 \%$ & $38.00^{\circ \cdots}$ & $-1.33 \%$ & 1.41 \\
\hline
\end{tabular}

For the SUR results, in the period of -5 to -1 , INS and PHA record significantly negative CAARs. The BIO and PHA record significantly negative CAARs in the announcement period of 0 and 1 . Finally, in the period of +2 and +5 , PHA and MED significantly negative CAARs. 


\subsubsection{Clinton's Presumptive Nomination}

During the pre-event period of -5 to -1 , the PHA has significantly negative CAAR. During the announcement period, the BIO and PHA have significantly negative CAARs. The HOS has significantly positive CAAR. During the post-event period, the HOS and PHA have significantly negative CAARs. The MED has significantly positive CAARs.

In a nutshell, PHA consistently suffers before, during, and after this event. When we look at the combined evidence associated with the presumptive nominations of both candidates, it appears that the market believes Clinton will win the race and the biggest loser will be PHA. The second one will be the BIO.

The SUR event study results do not suggest any significant abnormal returns, for the most part. However, the PHA has a significantly positive CAAR in the pre-event period; the BIO has a significantly negative CAAR during the announcement period, similar to the market model result; and in the post-event period, the MED has a significantly negative CAAR.

\subsubsection{Trump Wins the Election}

During the immediate pre-election period, all major headline news lopsidedly predict that Clinton will win the election. Based upon our previous predictions, a sector such as HOS is likely to be the over performer in the pre-election period of -5 to -1 . PHA and BIO are more likely to be the underperformers in this period. When the election results are revealed, the opposite will happen; PHA and BIO are the over-performers and HOS is likely to be the underperformer.

Our findings associated with this event, in general, support our prediction. We find that in the pre-event period of -5 to -1 , BIO and HOS have significantly positive CAAR. The PHA has a negative CAAR, although not significant. During the event period, the BIO and the PHA have significantly positive CAARs. But HOS has significantly negative CAAR. During the period of +2 to +5 , there is a certain degree of reversal effect; Both BIO and PHA have significantly negative CAARs. SUR results are similar to the market model results discussed above.

\subsubsection{Summary of Our CAAR Findings}

When we consider all the events together, a clear pattern appears. During the pre-election period, the BIO, INS, and PHA all suffer significantly negative CAARs. The HOS and MED fare reasonably well. Our interpretation is that the market takes a dim view on BIO, INS, and PHA when the consensus is that Trump stands no chance against Clinton. Clinton will win the election and Obamacare will continue under her administration. The status quo will be harmful for these three health care sectors.

When the election is over, the unthinkable happens. Investors immediately reassess the impact of the election. The fortune reverses for the BIO and PHA.

\subsection{Regression Analysis Results}

We present our regression results of estimating Model (2) in Table 5. The results show that the signs of both BIO and PHA are significantly positive. The magnitudes of the coefficients, 
0.056 and 0.061 , for BIO and PHA are similar to each other. Both are significant at the 0.01 significance level. The coefficients of the other two indicator variables, INS and HOS, are not significant. These results confirm our CAAR results. On the post-election day, BIO and PHA are the clear winners among five health care sectors.

Table 5. Multivariate regression results on the following model

$$
\begin{aligned}
\mathrm{CAR} & =\beta_{0}+\beta_{1} \mathrm{BIO}+\beta_{2} \mathrm{INS}+\beta_{3} \mathrm{HOS}+\beta_{4} \mathrm{PHA}+\beta_{5} \mathrm{FM} \_\mathrm{SZ}+\beta_{6} \mathrm{MTB}+\beta_{7} \mathrm{LEV} \\
& +\beta_{8} \mathrm{ROA}+\beta_{9} \mathrm{CS} \_\mathrm{TA}+\beta_{10} \mathrm{RD} \_\mathrm{TA}
\end{aligned}
$$

\begin{tabular}{lllll}
\hline Estimation of Regression Model $\left(\mathbf{F}=\mathbf{4 . 0 7}, \mathbf{P}<\mathbf{0 . 0 0 0 1}\right.$, Adjusted $\left.\mathbf{R}^{\mathbf{2}} \mathbf{0 . 1 1 5}\right)$ \\
\hline Variable & Predicted Sign & Parameter & Standard & Pr $>|\mathrm{t}|$ \\
\hline Intercept & Estimate & Error & \\
\hline BIO & + & -0.06014 & 0.02843 & 0.0355 \\
\hline INS & + & $0.05632 * * *$ & 0.02143 & 0.0092 \\
\hline HOS & - & -0.03517 & 0.04082 & 0.3898 \\
\hline PHA & + & -0.01393 & 0.03073 & 0.6508 \\
\hline FM_SZ & + & $0.06067 * * *$ & 0.01708 & 0.0005 \\
\hline MTB & + & 0.0103 & 0.00867 & 0.2359 \\
\hline LEV & + & $0.00388 *$ & 0.00207 & 0.0619 \\
\hline ROA & + & 0.01448 & 0.01584 & 0.3615 \\
\hline CS_TA & + & -0.01945 & 0.02189 & 0.3752 \\
\hline RD_TA & + & 0.03724 & 0.0243 & 0.1268 \\
\hline
\end{tabular}

$* * *, * *$, and $*$ denotes significant p-value at $1 \%, 5 \%$, and $10 \%$. The dependent variable is CAR, the cumulative abnormal returns over the event window [0,1]. The event date is November 9, 2016, the day of the elections. The main dependent variables are winners when the Affordable Healthcare Act is saved or improved and winners when the Affordable Healthcare Act (ACA) is repealed. Definition of variables are as follows: WINSAV, a dummy variable that equals one for firms that are winners when the ACA is saved or improved, zero otherwise. These are companies that operates in the hospital or nursing management industry. WINREP, a dummy variable that equals one for firms that are winners when the ACA is repealed, zero otherwise. These are companies that operates in the Biological Products, Health Insurance, Major Pharmaceutical, and Medical and dental products industries. BIO is a dummy variable that takes the value of one for firms that 
operate in the biological Product industry, otherwise zero. INS denotes a dummy variable that takes the value of one for firms that operate in the health insurance industry, otherwise zero. HOS is a dummy variable that equals one for firms that operate in the hospital or nursing management industry, otherwise zero. PHA is a dummy variable that equals one for firms that operate in the major pharmaceutical industry, otherwise zero. MED refers to a dummy variable that takes the value of one for firms that operate in the medical and dentist products industry, otherwise zero. FM_SZ is firm size, estimated as the natural logarithm of total assets. MTB is market to book value. It is computed as the ratio of market value of equity to book value of assets. LEV represents leverage, the ratio of debt to total assets. ROA is the ratio of earnings before interest and tax to total assets. CS_TA is the ratio of capital expenditure to total assets and RD_TA is the ratio of Research and expenditure to total assets.

Among the control variables, MTB is significantly positive at the 0.1 level. This is consistent with our earlier prediction that health care firms with higher MTB benefit more on the post-election days of 0 and +1 . None of the other control variables is significant.

\section{Conclusions}

The future of the ACA was one of the most contentious issues during the 2016 Presidential Campaign. The two candidates' positions on the issue were in sharp contrast with each other. On one hand, the Democratic candidate Clinton held the position that it could be improved. She would like to save and improve it. On the other hand, the Republican candidate Trump firmly believed that the ACA was totally broken. He wanted to repeal and replace it.

In this study, we survey the literature and document what the five major health care sectors experienced when the ACA was signed into law and when it was upheld in the Supreme court during the Obama administration. We find that HOS the winner of the ACA and INS, PHA, and $\mathrm{BIO}$ are the losers under the ACA. We conjecture, by way of extrapolation, that any 2016 presidential campaign event favoring Clinton would be good for the HOS and bad for the INS, PHA, and BIO sectors. However, any campaign event favoring candidate Trump would be bad for HOS, but good for INS, PHA, and BIO sectors.

We identify five important events during the 2016 Presidential campaign and examine the stock reactions of these five sectors pre-, during, and post-event abnormal returns. We first use the traditional market model regression and then the SUR regression to estimate the abnormal returns. It is not surprising that these two methods give us consistent results.

We find that, during the pre-election period, the BIO, INS, and PHA all suffer significantly negative CAARs. The HOS and MED fare reasonably well. Our interpretation is that the market takes a dim view on the BIO, INS, and PHA sectors when the consensus is that Clinton would win the election. The status quo would be harmful for these three healthcare sectors. When the election is over, the fortune reverses for the BIO and PHA. The regression results further confirm our event study results.

There are several important take-aways from this study. First, the election has a significant impact on the affected industry and the sectors/firms in the industry. However, even in the 
same broad industry, sectors/ firms fare differently. It is important to examine the impact of a policy in a more detailed and refined way.

Second, the stock market reacts expeditiously to expectations. In most of these events, we find that the abnormal returns are significantly positive for the sectors which will benefit from Clinton's presidency and negative for the sector which will be disadvantaged during the pre-election events. When the election is over, the investors immediately reassess the prospects of the health care sectors and react accordingly.

Thirdly, we use the findings from extant studies on the impact of the ACA on the health care firms to extrapolate our predictions. It appears that the evidence presented in this study is very consistent with our predictions. This could be a shortcut yet adequate way of articulating the hypotheses/ predictions in similar studies.

The ACA is one of the most contentious issue that is at the forefront of public policy debate in the US, and it continues to face challenges with respect to its implementation. Questions still exist as to whether the ACA should be completely replaced with a market-oriented reform or if it should just be revised. In this paper, we focus only on the five major health care sectors in the US. Hence, our results cannot be generalized to other sectors within the health insurance system. Future research can examine and compare the ACA to other health care legislations of countries with low-cost and effective healthcare systems. More research is also needed to understand and determine the optimal role of the government in healthcare.

\section{References}

Ababneh, M., \& Tang, A. (2013). Market reaction to health care law: An event study. International Journal of Accounting and Financial Reporting, 3(1).

Al-Ississ, M. M., \& Miller, N. H. (2013). What does health reform mean for the health care industry? Evidence from the Massachusetts special senate election. American Economic Journal: Economic Policy, 5(3), 1-29.

Bell, J. (2011). Stock prices, prediction markets, and information efficiency: Evidence from health care reform. Unpublished Manuscript.

Blau, B. M., Daines, B., Karl, J. B., \& Wade, C. (2016). Key Stakeholders' Stock Returns and the Affordable Care Act. Journal of Insurance Regulation, 35(9).

Borochin, P., \& Golec, J. (2016). Using options to measure the full value-effect of an event: Application to Obamacare. Journal of Financial Economics, 120(1), 169-193.

Brown, S. J., \& Warner, J. B. (1985). Using daily stock returns: The case of event studies. Journal of Financial Economics, 14(1), 3-31.

Dong, G. N. (2014). Health Care Reform and the Stock Market: Economic Impact, Growth Opportunity and Private Sector Investors. Journal of Health Care Finance, 41(2).

Fama, E. F., Fisher, L., Jensen, M. C., \& Roll, R. (1969). The adjustment of stock prices to new information. International Economic Review, 10(1), 1-21. 


\section{$\triangle 1$ Macrothink}

International Journal of Accounting and Financial Reporting

ISSN 2162-3082

2019, Vol. 9, No. 4

Geyman, J. P. (2015). A five-year assessment of the Affordable Care Act: Market forces still trump the common good in US health care. International Journal of Health Services, 45(2), 209-225.

Hall, M. A., \& McCue, M. J. (2016). How has the Affordable Care Act affected health insurers' financial performance?. Issue Brief (Commonwealth Fund), 18(1).

Hartley, J. (2012). Health Care Reform and Health Care Stocks: Evidence from the Affordable Care Act Supreme Court Ruling. Becker Friedman Institute for Research in Economics Working Paper (2012-009).

Hilliard, J. I., Liebenberg, A. P., Liebenberg, I. A., \& Ruhland, J. (2018). The Market Impact of the Supreme Court Decision Regarding the Patient Protection and Affordable Care Act: Evidence from the Health Insurance Industry. Journal of Insurance Issues, 41(2), 135-167.

Internal Revenue Service (IRS). (2018). Individual shared responsibility provision. Retrieved April, 4 2018, from https://www.irs.gov/affordable-care-act/individuals-and-families/individual-shared-responsibi lity-provision

Kliff, S. (2014). One in four Obamacare enrollees are young adults. Retrieved April, 42018 , from

https://www.washingtonpost.com/news/wonk/wp/2014/01/13/one-in-four-obamacare-enrolle es-are-young-adults-thats-below-the-target/?utm_term=.d5b0c9d394a 2

Nguyen, V., \& Tang, A. P. (2011). Did the 2008 short-sale ban prevent a market crash?. Journal of Applied Finance, 21(1).

Schipper, K., \& Thompson, R. (1983). The impact of merger-related regulations on the shareholders of acquiring firms. Journal of Accounting Research, 184-221.

Topping, S., Carroll, C., \& Lindley, J. T. (1997). The impact of health care reform on capital acquisition for hospitals. Financial Review, 32(4), 751-778.

Tuttle, B. (2016). 8 states where Obamacare rates are rising by at least 30\%. Retrieved April, 4 2018 , from http://time.com/money/4535394/obamacare-plan-premium-price-increases-2017-states/

\section{Copyright Disclaimer}

Copyright for this article is retained by the author(s), with first publication rights granted to the journal.

This is an open-access article distributed under the terms and conditions of the Creative Commons Attribution license (http://creativecommons.org/licenses/by/4.0/) 